\title{
Studies on the Permeation Properties of Geopolymer Concrete made with Sugarcane Bagasse Fiber
}

\author{
Pogula Anudeep ${ }^{1}$, T. Srinivas ${ }^{2}$, N.V.Ramana Rao $^{3}$ \\ ${ }^{1}$ P.G. Student, GRIET, Hyderabad, India. \\ ${ }^{2}$ Professor, GRIET, Hyderabad, India. \\ ${ }^{3}$ Professor, JNTUH, Hyderabad, India.
}

\begin{abstract}
Different fibers like steel, glass, basalt, coconut, sugarcane fibers are used to improve the tensile strength in the concrete. The sugarcane bagasse fiber (SCBF) is utilized in this paper work. This SCBF is the final extract of the sugar industries which contains the large fibers. The main objective of this paper is to study the effect of SCBF on the permeation properties of the geopolymer concrete (GPC) of G40 and compared to its equivalent M40 grade. The specimens of conventional concrete (CC) and conventional concrete with SBF (CCF) are casted and cured in the curing tanks for a period of 28 day, and the GPC and GPCF specimens are casted and oven cured at a temperature of $60^{\circ} \mathrm{C}$ for a time period of 24 hours and the test are performed after 28 days of ambient curing of the specimens. The permeation test like (Water absorption test, Sorptivity and Water Permeability test) are carried in the paper. Based on the results it is observed that the permeation properties of CCF and GPCF are more resistant when compared to the CC and GPC respectively.
\end{abstract}

\section{Introduction}

The concrete is the most commonly used cement mixture in the construction for its durability properties. In this aggressive environmental condition high performance concrete is required with high strength and durable properties. This can be achieved by the different trials of mix-proportions. Ordinary Portland Cement (OPC) is widely used in the production of the concrete mixture. The production of cement which emit the carbon-di-oxide. It also requires large amount of the natural resources. This results to the invention of the eco-friendly concrete, which is produced by the cementitious material like (fly ash and GGBS). These cementitious materials are activated by reacting with the alkaline liquids like (sodium hydroxide pellets and sodium sulphate liquid) ${ }^{*}$ with the required amount of water. This eco-friendly concrete is termed as the Geopolymer concrete.

Fly ash is the by-product of the thermal power plant. Based on the study, world-wide there is about 780 million tons of fly ash is produced every year. India itself produces about 220 million tons of fly ash every year. Ground granulated blast furnace slag (GGBS) is the by-product of iron industry. It is a low carbon-di-oxide material. Sodium/Potassium are used as the activators in the geopolymer concrete. Sodium is widely used for its low cost and it is easily available. The durability and mechanical properties of the geopolymer concrete is higher than the OPC concrete.

*Corresponding Author: srinu.tummala@gmail.com
The deterioration of concrete is commonly done due to the presence of water in its surroundings. The durability of the concrete is estimated by the rate at which the water is pass through the material under a constant pressure (Permeability). If more fluid penetrates into the concrete material, than the sample is said to be highly permeable which means low durable concrete. The concrete is said to be high durable, when the permeability of the concrete specimen is low. It means the quantity of water penetrated into the concrete specimen is low. According to the study the water penetrated in to the concrete specimen under a constant pressure up to the depth of $25 \mathrm{~mm}$ is considered as the durable concrete. The durability of the concrete is also determined in the easy way by the methods of water absorption capacity and water absorption rate (Sorptivity).

As all know that the concrete is high in compressive strength and weak in tensile strength. By the addition of fibers to the concrete, it is observed that the tensile strength of the concrete is improved. There is a further increase in the mechanical properties of the concrete, by the increase in the aspect ratio of the fiber. Fibers like glass, steel, coconut fiber, sugarcane bagasse fiber are used.

Sugarcane bagasse fiber (SCBF) is the by-product of the sugar industry after the extraction of juices from the sugarcane. This Sugarcane bagasse is the largest agricultural by-product in the world. And India stands $2^{\text {nd }}$ in the production of the sugarcane. This bagasse 
consists of fibers and small amount of water in it. The permeation properties of the concrete are reduced by the addition of SCBF. The bleeding of water is also minimized by the addition of fibers.

\section{Materials}

\subsection{Ordinary Portland Cement}

OPC of 53-grade is used in this experiment. The specificgravity of the cement is 3.15 and all other properties are found to be conforming various specifications as per IS:12629-1987.

\subsection{Fine Aggregate}

The fine aggregate of specific gravity 2.67, water absorption of $2.8 \%$ and which is belongs to zone- 2 as per code IS: $383-1970$. The river sand is collected from the local suppliers, which is passed through $475 \mathrm{~mm}$ IS sievewas utilized.

\subsection{Coarse Aggregate}

Crushed granites coarse aggregatewhich is passed through the $20 \mathrm{~mm}$ IS sieve and with an angular shaped coarse aggregate was used in this experiment. The specific gravity of coarse aggregate is measured to be 2.67 .

\subsection{Fly Ash}

Fly ash is the biproduct that is produced from the combustion of pulverized coal in the thermal industry. F-type fly ash is used in this experiment. Inthis experimental study,theflyashiscollected fromthe RMC plant atBollaram, hyderabad.

\subsection{Ground Granulated Blast Furnace Slag}

Ground Granulated Blast Furnace Slag (GGBS) is the final residue that producedfrom the steel industry. This GGBS is obtained by powdering the quenching molten iron slag from a blast furnace in water or steam. Here binder replaced with GGBS about $25 \%$ by mass. It is collected from RMC plant Bollaram.

\subsection{Water}

Waterwhich is freefrom impurities like chemicals components,oilsandotherof forms is used in the production of the concrete as per the codeIS:456:2000.

\subsection{Sodium Hydroxide}

Sodium Hydroxide is one of the major components that is used in the preparation of the geopolymer concrete. Sodium hydroxide is brought from the chemical sealers. And the specifications of Sodium hydroxide are tabulated in the following table 1 as given by the supplier. This Sodium Hydroxide is in the form of pellets.

Table 1. Shows Physical Properties of $\mathrm{NaOH}$

\begin{tabular}{|l|c|}
\hline Molar mass & $40 \mathrm{gm} / \mathrm{mol}$ \\
\hline Appearance & White solid \\
\hline Density & $2.1 \mathrm{gr} / \mathrm{cc}$ \\
\hline Melting point & $3180 \mathrm{Oc}$ \\
\hline Boiling point & $1390 \mathrm{Oc}$ \\
\hline $\begin{array}{l}\text { Amount of } \\
\text { heatliberated when } \\
\text { dissolved inwater }\end{array}$ & $267 \mathrm{cal} / \mathrm{gram}$ \\
\hline
\end{tabular}

\subsection{Sodium Silicate Solution}

The alkaline solution of Sodium silicate liquid used in this experiment. This solution plays a majorroleinthepolymerizationprocess. Thismaterialis bought from the localchemical dealers in the Hyderabad. The Specifications of the sodium silicate solution are tabulatedin the followingtable2, asgivenbysuppliers.

Table 2. Properties of $\mathrm{Na} 2 \mathrm{SiO} 3$ Solution

\begin{tabular}{|c|c|}
\hline Specific gravity & 1.57 \\
\hline Molar mass & $122.06 \mathrm{gm} / \mathrm{mol}$ \\
\hline $\mathrm{Na}_{2} \mathrm{O}$ (by mass) & $14.35 \%$ \\
\hline $\mathrm{SiO}_{2}$ (by mass) & $30.00 \%$ \\
\hline Water (by mass) & $55.00 \%$ \\
\hline $\begin{array}{c}\text { Weight ratio }\left(\mathrm{SiO}_{2} \text { to }\right. \\
\left.\mathrm{Na}_{2} \mathrm{O}\right)\end{array}$ & 2.09 \\
\hline Molarity ratio & 0.97 \\
\hline
\end{tabular}

\subsection{Super Plasticizer}

Sulfonated Naphthalene Formaldehyde (SNF) super plasticizer isaddedtoimprovethe workability properties of concrete. The superplasticizer utilized in this study is $2 \%$ ofthe binder.

\section{Experimental Investigation}

\subsection{General}

An objective of this paper is to study the permeation properties like water absorption, sorptivity and water permissible test on geopolymer concrete of grade G40. Which is made with sugarcane bagasse fiberand also to compare the results of controlled concrete made with sugarcane bagasse fiber. And also, withthe geopolymer concrete and controlled concrete of similar grades. $100 \mathrm{~mm} \times 100 \mathrm{~mm} \times 100 \mathrm{~mm}$ sized cubes were casted and settled for a period of 24 hours, then the specimens were oven curedfor the period of 24 hours at $60^{\circ} \mathrm{C}$ and rest of the time cured under the ambient curing. 


\subsection{Mixingand Casting of Geopolymer Concrete}

Geopolymerconcrete isprepared byreplacing the cement intheconventional concrete by Cementous materials like fly ash and GGBS. Pan mixer is used to prepare the concrete in the laboratory. These materials were mixed in dry condition by utilizing the panmixer for a duration of 2 minutes, then alkaline liquid (sodium hydroxide and sodium silicate)is addedwith the superplasticizer,and anadditional amount of water is added if needed. This mixture of materialsis then added to the dry mixture, and allowed to mix for a period of 2 minutes. The fresh geopolymer concrete was castedby following the same standard strategies asof controlled concrete. Theworkability of the concrete is measured by slumptest.

The test to be conducted on permeation properties are

1. Sorptivity test

2. Water absorption test

3. Water Permeability

\subsection{Sorptivitytest}

GPC of grade 40 is used with SCBF. The objective of this test is to indicating the rate of absorption or sorptivity in concrete. The specimen is sealed from all the sides leaving the water contacting surface and its opposite side. The coefficient of Sorptivity (K)is obtained

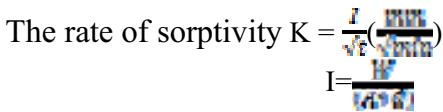

$\mathrm{W}=$ Amount of water absorbed in kilogram $\mathrm{A}=$ Cross sectionalarea of specimen in contact withwater

$\mathrm{d}=$ density of water $\left(1000 \mathrm{~kg} / \mathrm{m}^{2}\right)$

Table 3. SorptivityCoefficient of GPC and CC With and Without Fibers

\begin{tabular}{|r|r|r|r|r|r|}
\hline \multirow{2}{*}{ S.NO } & \multirow{2}{*}{$\begin{array}{c}\text { Time } \\
\text { in mins }\end{array}$} & \multicolumn{4}{|c|}{ Sorptivity value $\left(\mathrm{mm} / \mathrm{min}^{0.5}\right)$} \\
\cline { 3 - 6 } & & CC & CCF & GPC & GPCF \\
\hline 1 & 15 & 0.074 & 0.064 & 0.055 & 0.049 \\
\hline 2 & 30 & 0.065 & 0.057 & 0.045 & 0.037 \\
\hline 3 & 60 & 0.058 & 0.045 & 0.039 & 0.031 \\
\hline 4 & 120 & 0.052 & 0.041 & 0.031 & 0.027 \\
\hline 5 & 240 & 0.048 & 0.035 & 0.028 & 0.023 \\
\hline 6 & 360 & 0.041 & 0.032 & 0.023 & 0.019 \\
\hline 7 & 1440 & 0.038 & 0.031 & 0.025 & 0.021 \\
\hline 8 & 2880 & 0.035 & 0.029 & 0.019 & 0.017 \\
\hline 10 & 3600 & 0.032 & 0.027 & 0.018 & 0.016 \\
\hline
\end{tabular}

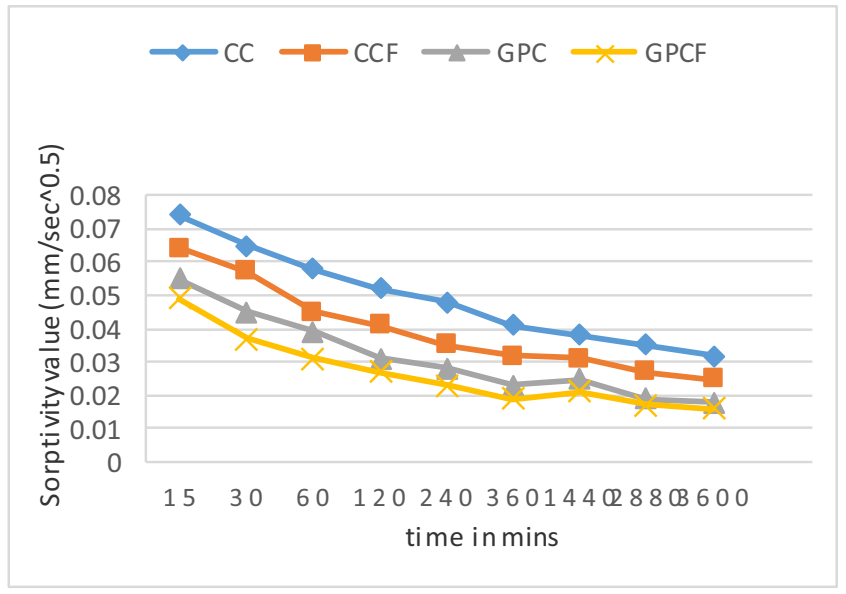

Fig. 1. Shows Sorptivity Coefficient with Time $V_{t}$

\subsection{WaterAbsorption}

Water absorption rate of the concrete can be identified by this test, when it is fully submerged in water. The absorption rate can be calculated by

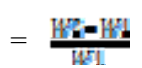

$\mathrm{W} 1=$ Dry weight of cube $\mathrm{W} 2=$ wet weight of cube The $\%$ of water absorption is identified from the above equation

Table 4. \%OfWeightAbsorption with Timefor the GPC and CC With and Without Fibers

\begin{tabular}{|r|r|r|r|r|r|}
\hline \multirow{2}{*}{ S.NO } & \multirow{2}{*}{$\begin{array}{c}\text { Time } \\
\text { in min }\end{array}$} & \multicolumn{5}{|c|}{ \% Water absorption } \\
\cline { 3 - 6 } & & CC & CCF & GPC & GPCF \\
\hline 1 & 0 & 0 & 0 & 0 & 0 \\
\hline 2 & 15 & 0.79 & 0.71 & 0.61 & 0.55 \\
\hline 3 & 30 & 2.51 & 2.39 & 1.51 & 1.44 \\
\hline 4 & 60 & 2.92 & 2.67 & 2.31 & 2.11 \\
\hline 5 & 120 & 3.75 & 3.52 & 3.41 & 3.25 \\
\hline 6 & 240 & 4.38 & 4.11 & 4.12 & 3.92 \\
\hline 7 & 1440 & 4.42 & 4.22 & 4.27 & 3.98 \\
\hline 8 & 2880 & 4.43 & 4.25 & 4.35 & 4.07 \\
\hline 9 & 3600 & 4.43 & 4.27 & 4.35 & 4.08 \\
\hline
\end{tabular}




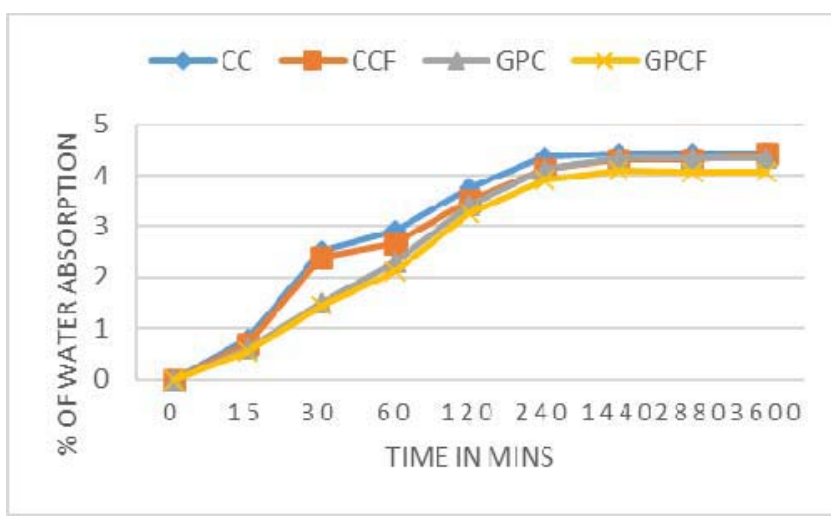

Fig. 2. Shows the \% of Water Absorption with Time

\subsection{Water Permeability}

The Waterpermeability test for concrete is done according to IS $3085: 1965$. The permeabilityapparatus used wasa single-celled tester consisting of a singletestcells, a pressure chamber and air compressor. Water suppliedinto the test samples with a constant pressure head. GPC specimens and CC specimens with and without fibers are casted with the diameter\& height $150 \mathrm{~mm}$ and $170 \mathrm{~mm}$ respectively and cured for a period of 28 days. These specimens are loaded in to the specially designed cells and $15 \mathrm{~kg} / \mathrm{cm}^{2}$ of constant air pressureismaintained throughout the test byusing an air compressor for a given interval of time. The standard pressure head of $10 \mathrm{~kg} / \mathrm{cm}^{2}$ is applied on the water. At the periodic intervals, the quantity of percolated water is collected and measured. At the beginning, the rate of water intake is higher than the rate of water outflow. The steady state of flow is reached in a short period of time. At this steady state flow, the rate of water intake and rate of water outflow becomes equal. The outflow is stabilized by reaching its maximum level. There is a gradual drop in the both in flow and outflow with an additional passage of time. This test is carried out for a period of 100 hours, after the steady state of flow is registered. The outflow is finalised as an average of the outflows measured during this period of 100 hours. According to the Darcy's law of a falling water head, the coefficient of permeability at steady state flow condition is calculated for the 28days aged specimen using the following formula. The coefficient of permeability is represented by $\mathrm{K}$.

\section{$\frac{Q}{A+T^{*}+(F / E)}$}

$\mathrm{K}=$ Coefficient of the Permeability $(\mathrm{m} / \mathrm{sec})$

$\mathrm{Q}=$ The quantity of water collected over entire test period(millilitres)

$\mathrm{T}=$ Time is considered in second $(100 \times 60 \times 60 \mathrm{sec}=$ $360000 \mathrm{sec}$ )

$\mathrm{A}=$ Area of the specimen face $\left(\mathrm{m}^{2}=0.01767 \mathrm{~m}^{2}\right)$

Waterpressure $=10 \mathrm{~kg} / \mathrm{cm}^{2}=106$ Pa1Pascal of pressure $=0.0001 \mathrm{~m}$ of pressure head Pressure Head $=100 \mathrm{~m}$ (throughout the test it will be constant)

$\mathrm{H} / \mathrm{L}=$ ratio of pressure head to thickness of the specimen in metre $=100 \mathrm{~m} / 0.15 \mathrm{~m}=666.67$
Table 5. The Coefficient of Permeability of GPC and CC With and Without Fibers at Age 28 days

\begin{tabular}{|l|r|r|l|l|}
\hline $\begin{array}{l}\text { Type Of } \\
\text { Specimen }\end{array}$ & $\begin{array}{l}\text { Pressur } \\
\text { e Head }\end{array}$ & $\begin{array}{l}\text { Quantity } \\
\text { of Water } \\
\text { Collecte } \\
\text { d d(m) }\end{array}$ & $\begin{array}{l}\text { Coefficient } \\
\text { of } \\
\text { Permeabilit } \\
\mathbf{y} \\
\mathbf{X ~ 1 0 - 9} \\
\mathbf{m} / \mathbf{s e c}\end{array}$ & $\begin{array}{l}\text { \% } \\
\text { Decrease } \\
\mathbf{d}\end{array}$ \\
\hline CC & 100 & 6892 & 1.625 & - \\
\hline CCF & 100 & 6625 & 1.562 & 3.872 \\
\hline GPC & 100 & 6584 & 1.552 & - \\
\hline GPCF & 100 & 6124 & 1.444 & 6.958 \\
\hline
\end{tabular}

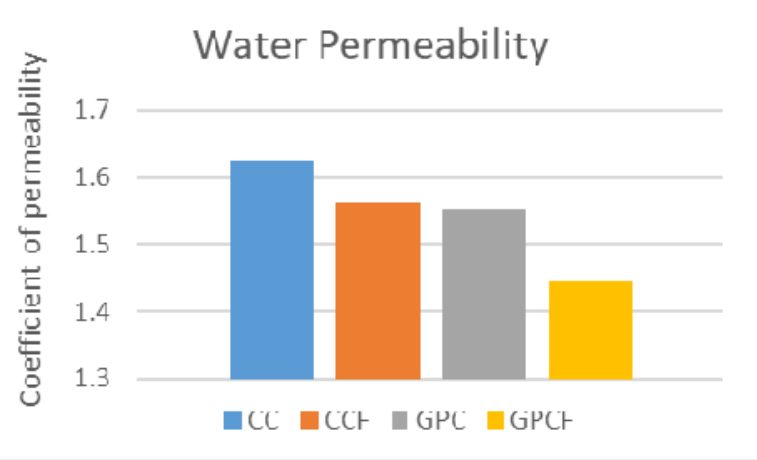

Fig. 3. Shows the Coefficient of Permeability of GPC and CC With and Without Fibers

Table 6. Coefficient of Water Permeability Ranges as per IS: 3085-1965

\begin{tabular}{|l|l|l|l|l|}
\hline $\begin{array}{l}\text { Water } \\
\text { Permeability }\end{array}$ & VeryLow & Low & Medium & High \\
\hline $\begin{array}{l}\text { Coef of } \\
\text { permeability } \\
\left.\text { (x } 10^{-9} \mathrm{~m} / \mathrm{sec}\right)\end{array}$ & $<0.5$ & $0.5-$ & $1.0-2.0$ & $>2.0$ \\
\hline
\end{tabular}

\section{Conclusion}

1. It is observed that the permeability of $\mathrm{CCF}$ and GPCF are reduced by $3.87 \%$ and $6.95 \%$ respectively when compared to CC and GPC.

2. Sorptivity of CCF is reduced by $15.62 \%$ when compared with CC.

3. By addition of SCBF to the GPC the sorptivity is minimized by $11.11 \%$.

4. The water absorption capacity of $\mathrm{CCF}$ and GPCF are reduced by $3.61 \%$ and $6.20 \%$ respectively when compared to the CC and GPC when treated with water for a period of 28 days.

5. By the addition of the SCBF to the CC and GPC, the permeation properties of the concretes like Sorptivity, Water absorption and Water permeability are decreased. 


\section{References}

1. Henry A Colorado, John F Zapata, J. Mater. Environ. Sci, 10, 1162-1171 (2019)

2. Tanveer Singh Bains, Khushpreet Singh, IJTEE, 8, 7, (2019)

3. T. Srinivas, P. Manoj Anand, IJITEE, 8, 12, (2019)

4. Ankur Laxman Yadav, V. Sairam, K. Srinivasan, L. Muruganandam, Const. and Buil. Mate, 258, 119231 (2020)

5. Ankur Laxman Yadav, V. Sairam, L. Muruganandam, K. Srinivasan, Jour. of Cle. Prod, 245,118854, (2020)

6. Raju, N.A., Suresh Kumar, T. International Journal of Innovative Technology and Exploring Engineering, 8(11), pp. 3860-3864, 2019

7. Francisco Hernandez-Olivares, Rosa Elizabeth Medina-Alvarado, Xavier Eduardo BurneoValdivieso, Alonso Rodrigo Zuniga-Suarez, Cons. and Buil. Mate., 247, 118451 (2020)

8. Zuzhong Li, Xuelei Zhang, Chunguang Fa, Yayun Zhang, Jianping Xiong, Huaxin Chen, Const. and Buil. Mate., 248, 118648, (2020)

9. K. satyanarayana, S. K. Singh, T. Buddi, K. Anil and A. Ul Haq, Advances in Materials and Processing Technologies, 6(2), 365 (2020)

10. Arslan Akbar, Furqan Farooq, Muhammad Shafique, Fahid Aslam, Rayed Alyousef, Hisham AbdulJabbar, Jour. of Buil. Eng, 33, 101492 (2021)

11. T.Srinivas and M. Abinay Raj, Int. J. of Eng.and Adv. Tech. (IJEAT), ISSN: 2249 - 8958, Volume-8 Issue-6 (2019)

12. T.srinivas and P. Manoj Anand, Int. J. of Innov. Tech. and Explor. Eng.g (IJTEE), ISSN: 22783075, Volume-8 Issue-12 (2019)

13. T.Srinivas and G. Sukesh Reddy, Int. J. of Eng.and Adv. Tech. (IJEAT), ISSN: 2249 - 8958, Volume-9 Issue-1 (2019)

14. T.Srinivas and R. N. Koushik, Int. J. of Innov. Tech. and Explor. Eng.g (IJITEE), ISSN: 22783075, Volume-8 Issue-12 (2019), PP 112-117.

15. K. Sai Gopi, Dr. T. Srinivas and S. P. Raju V, E3S Web of Conferences ICMED 184, 01084GRIET, 28-29 February, https://doi.org/10.1051/e3sconf/2020184011084( 2020)

16. Jagannadha Kumar, M.V., Jagannadha Rao, K., Dean Kumar, B., Srinivasa Reddy, V., Int. J. of Civil Eng. and Tech., 9(7), pp. 1133-1141 (2018)

17. Ganta, J.K., Seshagiri Rao, M.V., Mousavi, S.S., Srinivasa Reddy, V., Bhojaraju, C., Structures 28, pp. 956-972 (2020)

18. M. Kavitha, P. B. Bobba and D. Prasad, 20167 th India International Conference on Power Electronics (IICPE), 2016, pp. 1-6

19. Naidu, K.S.S.T., Rao, M.V.S., Reddy, V.S., Int. J. of Innov. Tech. and Explor. Eng.g (IJITEE), 8(9 Special Issue 2), pp. 641-642 (2019)

20. Chandana Priya, C., Seshagiri Rao, M.V., Srinivasa Reddy, V., Int. J. of Civil Eng. and Tech., 9(11), pp. 2218-2225 (2018)
21. Satya Sai Trimurty Naidu, K., Seshagiri Rao, M.V., Srinivasa Reddy, V., Int. J. of Civil Eng. and Tech., 9(11), pp. 2383-2393 (2018)

22. Supriya, Y., Srinivasa Reddy, V., Seshagiri Rao, M.V., Shrihari, S., Int. J. of Rec. Tech. and Engi., 8(3), pp. 5381-5385 (2019)

23. Kotkunde, N., Krishna, G., Shenoy, S.K., Gupta, A.K., Singh, S.K. International Journal of Material Forming, 10 (2), pp. 255-266 (2017)

24. Govardhan, D., Kumar, A.C.S., Murti, K.G.K., Madhusudhan Reddy, G. Materials and Design, 36, pp. 206-214. (2012)

25. Karthik Rao, R., Bobba, P.B., Suresh Kumar, T., Kosaraju, S. Materials Today: Proceedings, 26, pp. 3085-3089, 2019

26. Kumar, P., Singhal, A., Mehta, S., Mittal, A. Journal of Real-Time Image Processing, 11 (1), pp. 93-109. (2016)

27. Raghunadha Reddy, T., Vishnu Vardhan, B., Vijayapal Reddy, P. International Journal of Applied Engineering Research, 11 (5), pp. 3092$3102(2016)$

28. S. U.M. Rao,T.H. Rao, K. Satyanarayana, and B. Nagaraju, Materials Today: Proceedings, 5(2), 4958 (2018)

29. Hussaini, S.M., Krishna, G., Gupta, A.K., Singh, S.K. Journal of Manufacturing Processes, 18, pp. 151-158 (2015) 